\title{
Efficacy of Levamisole in children with Frequent Relapsing and Steroid Dependent Nephrotic Syndrome at Tertiary Care Center-Karachi
}

\author{
Khemchand N Moorani ${ }^{1}$, Aasia Mohammad Zubair ${ }^{2}$, \\ Nanga Ram Veerwani ${ }^{3}$, Harnam Jaichand Hotchandani ${ }^{4}$
}

\begin{abstract}
Objectives: To determine the effectiveness of levamisole in maintaining remission of proteinuria in children with frequent relapsing and steroid dependent nephrotic syndrome (FR/SDNS).

Methods: This observational study on 81 children with FR /SDNS was carried out from June 2007 - June 2017 at The Kidney Center-Postgraduate Training Institute, Karachi-Pakistan. Levamisole (leva) along with low dose prednisolone on alternate day (AD) was used after induction of remission with daily oral prednisolone in children with FR/ SDNS for 6-36 months. Patients with steroid resistance were excluded. Data was analyzed using descriptive statistics.

Results: Eighty-one patients with FR (66) or SD (15) received levamisole treatment. Mean age at diagnosis was $3.72 \pm 2.33$ years. Levamisole was used on AD in $59.25 \%$ and daily in $40.74 \%$ of cases. Twenty-four could not complete six months and were excluded, 57 patients completed treatment duration of $15.68 \pm 9.93$ months and 51 post-leva follow-up of $11.70 \pm 11.23$ months. Mean cumulative prednisolone dose per patient before, on-leva and post-leva was $3389.81 \pm 2785.22,2471.97 \pm 2024.98$ and $661.37 \pm 905.37 \mathrm{mg}$ respectively. Mean relapse rate per year before leva, on -leva and post -leva was $3.30 \pm 0.50,0.98 \pm 1.1$ and $0.79 \pm 1.27$ respectively. Levamisole was effective in $90 \%$ of patients. During post-leva follow up, $76.4 \%$ patients, maintained remission, whereas $23.5 \%$ behaved as FR/SD and require further immunosuppressive therapy.

Conclusions: Levamisole was effective in maintaining remission in $90 \%$ while on treatment, whereas it maintained remission after discontinuation in $76.4 \%$ cases. Levamisole may be used as first steroid sparing agent before other immunosuppressive therapies in children with FR/SDNS. Further studies are required for optimal duration and dosage schedule.
\end{abstract}

KEYWORDS: Remission of proteinuria, Frequent relapsing, Steroid dependent nephrotic syndrome, Relapses, Levamisole.

doi: https://doi.org/10.12669/pjms.36.6.2337

How to cite this:

Moorani KN, Zubair AM, Veerwani NR, Hotchandani HJ. Efficacy of Levamisole in Children with Frequent Relapsing and Steroid Dependent Nephrotic Syndrome at Tertiary Care Center-Karachi. Pak J Med Sci. 2020;36(6):1193-1198. doi: https://doi.org/10.12669/pjms.36.6.2337

This is an Open Access article distributed under the terms of the Creative Commons Attribution License (http://creativecommons.org/licenses/by/3.0), which permits unrestricted use, distribution, and reproduction in any medium, provided the original work is properly cited.

\section{Correspondence:}

Khemchand N Moorani,

Professor of Pediatric Nephrology,

National Institute of Child Health (NICH),

Jinnah Sindh Medical University,

Karachi, Pakistan.

E-mail: khemchandn@hotmail.com

* Received for Publication:

* $1^{\text {st }}$ Revision Received:

* $\quad 2^{\text {nd }}$ Revision Received:

* Final Revision Accepted:
February 10, 2020

March 16, 2020

June 23, 2020

June 25,2020

\section{INTRODUCTION}

Majority of children with nephrotic syndrome are steroid sensitive minimal change disease(MCD), but after initial response to standard corticosteroid therapy, more than $80 \%$ experience relapses. ${ }^{1}$ Among the steroid sensitive children, 40-60\% experience frequent relapses (FR) and 30-50\% of MCD become steroid dependent (SDNS). ${ }^{1}$ Patients with FR and SD who require repeated 
courses of steroid are at risk of long -term steroid toxicities and serious infections, thus may affect the qualities of life. ${ }^{2}$ In children with FRNS, steroids can be stopped intermittently but not in SDNS and patients with SD are more vulnerable to steroid toxicity and require aggressive immunosuppressive protocols. ${ }^{1,3}$

Management strategies for children with FR and SDNS, include prolonged use of low dose oral prednisolone (OP) on alternate day (AD), levamisole along with $\mathrm{AD}$ low dose OP, cyclophosphamide (CPM) for 2-3 months, mycophenolate mofetil (MMF) and calcineurin inhibitors (CNIs) like cyclosporine or tacrolimus. ${ }^{4-6}$ Rituximab (anti-CD20) has been used in developed countries for difficult cases of FRNS /SDNS.7

Minimal change nephrotic syndrome is a T-cell disorder with type 2 immune response in active disease state and levamisole exerts an immunomodulatory effect, upregulating Th1 and CD4 $\mathrm{T}$ cells through activation of interleukin-18 and interferon- gamma respectively. ${ }^{8}$ There are studies published locally on various aspects of nephrotic syndrome but only one on efficacy of levamisole in children with FR/SDNS. ${ }^{9-11}$

We in this study report our experience of levamisole as the first-line alternative steroid sparing agent in FRNS and SDNS. Objective of the study was to determine the effectiveness of levamisole in maintaining remission of proteinuria in children with FR and SDNS.

\section{METHODS}

This observational study comprises of 81 children with either FR or SDNS who received levamisole over 10 years from June 2007 - June 2017 at The Kidney Center-Postgraduate Training Institute, Karachi-Pakistan. Institutional Ethical Review Board approval (No.91-NEPH-012020 (EXEMPTION) was taken. Formal consent from parent or patients was taken before starting treatment with levamisole. Convenient sampling technique was used for this study. Initial episode of NS was treated with daily OP $\left(60 \mathrm{mg} / \mathrm{m}^{2}\right)$ for $4-8$ weeks followed by $40 \mathrm{mg} / \mathrm{m}^{2}$ on AD for 12 24 weeks. Based on subsequent number and frequency of relapses, patients were categorized as FR if $>2$ relapses in 6 months or $>4$ in a 12 months' period and SDNS if child develops two consecutive relapses on steroid therapy or within 14 days of switching to AD prednisolone. ${ }^{12}$

Levamisole was used for 6-36 moths in a dose of 2-2.5 mg/ kg/day either daily or AD along with low dose OP (0.25-0.5 mg/ kg dose) on AD after induction of remission with daily OP for relapse. Patients were followed initially at one month with spot urine protein creatinine ratio (spot Ur PCR) and complete blood count, subsequently 2-3 monthly with tapering of AD prednisolone from $1.5 \mathrm{mg} / \mathrm{kg}$ to $1 \mathrm{mg} / \mathrm{kg}$ at one month then $0.5 \mathrm{mg} /$ $\mathrm{kg}$ on alternate day for first 3-6 months and then $0.25 \mathrm{mg} / \mathrm{kg}$ on alternate day. Children who were not able to complete first six months due to noncompliance to levamisole or those whose parents opted for alternate immunosuppressive therapy were excluded from final analysis.

Patients with initial steroid resistance were also excluded. Data including patient's age, body surface area (BSA), height, weight, indications (FR/SD), dose of levamisole, number of relapses and cumulative dose of OP before, on-leva and post- leva treatment were collected on predesigned proforma and analyzed using descriptive statistics on SPSS version 16. Qualitative variables like gender, type of NS and treatment outcome were represented by frequencies and percentages whereas quantitative variables like age were represented by mean \pm standard deviation. Student-T -test was applied to compare the relapse rate and cumulative steroid dose before, on-leva and post -leva follow-up. P-value less than 0.05 was considered as significant.

\section{RESULTS}

There were $81(62.32 \%)$ out of 130 children with SSNS who received levamisole during the study period. The characteristics of children who received leva during study period are shown in Table-I. Among 81 patients, 66 (81.48\%) were FR and $15(18.51 \%)$ were SDNS. This table also shows that the mean age of study participants at initial diagnosis and at time of analysis was $3.72 \pm 2.33$ and $8.44 \pm 3.70$ years respectively.

Levamisole was used on AD dosage in 48 (59.25\%) patients during early years and daily dose in $33(40.74 \%)$ cases during later years. Among 81 enrolled patients, 24 could not complete minimum duration of six months so excluded, 57 patients completed leva-treatment of $15.68 \pm 9.93$ months and 51 cases were followed for $11.70 \pm 11.23$ months after discontinuation of leva (Table-I).

The mean dose of levamisole used per patient was $1.73 \pm 0.67 \mathrm{mg} / \mathrm{kg}$ and mean duration of levatreatment was $15.68 \pm 9.93$ months. This table also reveals that the mean cumulative doe of 
Table-I: Characteristics of patients on Levamisole

Treatment in Frequent Relapsing and Steroid Dependent Nephrotic Syndrome. $n=81$.

\begin{tabular}{lc}
\hline Variable & $N(\%) /$ mean $\pm S D$ \\
\hline Gender & \\
Male & $48(59.3 \%)$ \\
Female & $33(40.7 \%)$ \\
Age at diagnosis (years) & $3.72 \pm 2.33$ \\
Present age (years) & $8.44 \pm 3.70$ \\
Present weight $(\mathrm{kg})$ & $25.18 \pm 11.27$ \\
Present height (cm) & $118.11 \pm 20.25$ \\
Present BSA (msq) & $0.88 \pm 0.27$ \\
Indications of levamisole & \\
FRNS & $66(81.4 \%)$ \\
SDNS & $15(18.5 \%$ \\
Levamisole dose (mg/kg/day) & $1.74 \pm 0.68$ \\
Duration of levamisole (months) & $15.68 \pm 9.39$ \\
Post-leva follow up period(months) & $11.70 \pm 11.23$ \\
Cumulative steroid dose(mg) & \\
Pre-leva & $3389.81 \pm 2785.22$ \\
On-leva & $2471.97 \pm 2024.98$ \\
Post-leva & $661.37 \pm 905.37$ \\
Relapse rate per year & \\
Pre-leva & $3.30 \pm 0.50$ \\
On-leva & $0.98 \pm 1.1$ \\
Post-leva & $0.79 \pm 1.27$ \\
\hline
\end{tabular}

prednisolone per patient before treatment with leva (12 months), on -leva (15.68 \pm 9.93 months) and during post -leva follow up was 3389.81 \pm 2785.22 , $2471.97 \pm 2024.98$ and $661.37 \pm 905.37$ respectively. Mean relapse rate per year before leva, on -leva and post -leva was 3.30 $\pm 0.50,0.98 \pm 1.1$ and $0.79 \pm 1.27$ respectively.

Relapse rate decreased significantly $(p=0.001)$ with the use of levamisole in children with $\mathrm{FR} / \mathrm{SD}$ and reduction in cumulative steroid dose from $3389.81 \pm 2785.22 \mathrm{mg}$ before leva to
Table-III: Outcome of levamisole in children with frequent relapsing and steroid dependent nephrotic syndrome.

\begin{tabular}{lc}
\hline \multicolumn{2}{c}{ On -levamisole outcome $(\mathrm{N}=57)$} \\
\hline Effective & $46(90.1 \%)$ \\
Not effective & $11(19.2 \%)$ \\
\multicolumn{1}{c}{ Post- levamisole outcome $(\mathrm{N}=51)$} \\
Maintained remission & $39(76.4 \%)$ \\
Frequent relapsing/steroid dependent & $12(23.5 \%$ \\
\hline
\end{tabular}

$2471.97 \pm 2024.98 \mathrm{mg}$ while on treatment and to $661.37 \pm 905.37 \mathrm{mg}$ during post-leva treatment period. However, there was no significant reduction in cumulative steroid dose as shown in Table-II.

Outcome of children treated with levamisole is shown in Table-III. There was no relapse or had less than two relapses on -leva in $46(90.1 \%)$ and considered as effective whereas $11(19.2 \%)$ had $>2$ relapses in six months and declared as not effective. During post-leva follow-up period of $11.70 \pm 11.23$ months, 39(76.4\%) patients out of 51 maintained remission whereas, $12(23.5 \%$ behaved as FR/SD and require further immunosuppressive therapy. There was pancytopenia and allergic rashes each in one child.

\section{DISCUSSION}

Management of children with steroid sensitive nephrotic syndrome who behave as FR or $\mathrm{SD}$ is challenging and various immunosuppressant agents have been evolved during last two decades ${ }^{1,3-5}$ Options of sequential immunosuppressive therapy for children with FR /SD include use of low dose OP on AD, levamisole, cyclophophosphamide, CNIs (cyclosporin and tacrolimus), mycophenolate mofiteil and more

Table-II: Cumulative steroid dose and relapse rate in children with Frequent Relapsing and Steroid Dependent Nephrotic Syndrome.

\begin{tabular}{lccc}
\hline Duration (months) & $\begin{array}{c}\text { Cumulative dose of steroid } \\
(\text { mg/patient }) \text { Mean } \pm S D^{* *}\end{array}$ & $\begin{array}{c}\text { No. of relapses per } \\
\text { patient Mean } \pm S D\end{array}$ & P value \\
\hline Pre-Leva (12 months) $\mathrm{n}=81$ & $3389.81 \pm 2785.22$ & $3.30 \pm 0.50$ \\
On- leva (15.68 \pm 9.93 months) $\mathrm{n}=57$ & $2471.97 \pm 2024.98$ & $0.98 \pm 1.1$ & 0.001 \\
Post-Leva (12 months) $\mathrm{n}=51$ & $661.37 \pm 905.37$ & $0.79 \pm 1.27$ \\
\hline
\end{tabular}

*Significant for relapse rate (pre, on and post leva relapse rate).

**Not significant for cumulative dose. 
Table-IV: Comparison of our study results with an Indian Study. ${ }^{17}$

\begin{tabular}{|c|c|c|}
\hline Characteristics & Our study $(n=81)$ & Indian study $(n=97)$ \\
\hline Type of NS: FR/SD & $66 / 15$ & $62 / 35$ \\
\hline Gender Male & $48(59.2 \%)$ & $53(54.63 \%)$ \\
\hline Mean age at diagnosis & $3.72 \pm 2.33$ & $2.8 \pm 1.45$ \\
\hline \multicolumn{3}{|c|}{ Dosage schedule: $(2-2.5 \mathrm{~g} / \mathrm{kg} /$ day $)$} \\
\hline Daily dose & 33 & Single Daily Dose \\
\hline Alternate day & 48 & \\
\hline \multicolumn{3}{|l|}{ Cumulative steroid dose } \\
\hline Pre-Leva & $3389.81 \pm 2785.22$ & $4109.29 \pm 1154$ \\
\hline On -Leva & $2471.97 \pm 2024.98$ & $2491.8 \pm 694$ \\
\hline Post-Leva & $661.37 \pm 905.37$ & $660.7 \pm 10.7$ \\
\hline \multicolumn{3}{|l|}{ Relapse Rate } \\
\hline Pre-Leva $(\mathrm{n}=81)$ & $3.30 \pm 0.46$ & $2.41 \pm 0.5$ \\
\hline On-Leva $(\mathrm{n}=57)$ & $0.84 \pm 0.94$ & $1.3 \pm 0.7$ \\
\hline Post-Leva $(n=51)$ & $1.06 \pm 0.99$ & $0.48 \pm 0.8$ \\
\hline \multicolumn{3}{|l|}{ Outcome on Leva $(n=57)$} \\
\hline Effective & $46(80.70 \%)$ & $77.3 \%$ \\
\hline Not effective & $11(19.29 \%)$ & $15 \%$ \\
\hline
\end{tabular}

recently rituximab. ${ }^{3-7}$ Currently, there is still no consensus on whether one immunosuppressive agent is more effective than other. ${ }^{1,3,4}$

Levamisole is an immunomodulant imidazothiol-derived anthelminthic agent and has been the center of current research in FR and SDNS. ${ }^{13,14}$ The efficacy and safety of levamisole has been documented in many observation studies and in randomized controlled trials (RCTs) from many European and Asian countries including Pakistan. ${ }^{6,10,14-16}$

We recently published data on experience of immunosuppressive agents in primary nephrotic syndrome at tertiary care center but current study aimed at determining the effectiveness of using levamisole in children with FR and SD. ${ }^{12}$

It was found that use of leva in children with FR and SDNS was effective in maintaining relapse free remission over 12 months while on treatment and more than 12 months after discontinuation of levamisole (Table III and IV). Levamisole use resulted in significant reduction of relapse rate per patient, from $3.30 \pm 0.50$ to $0.98 \pm 1.1$ on levamisole and even after discontinuation of levamisole to $0.79 \pm 1.27(p=0.001)$. (Table-III). Similar response with use of leva as steroid sparing agent in FR and SDNS have been reported in many studies. ${ }^{15-18}$

Levamisole has been used in different dosage schedule (either daily single or on alternate day) and in dose range $(2-2.5 \mathrm{mg} / \mathrm{kg} /$ day) for wide range of duration (12-24 months) in different ethnic populations with more or less similar outcome without significant adverse events. ${ }^{15-20}$ During earlier years, levamisole was used as alternate day levamisole $2.5 \mathrm{mg} / \mathrm{kg}$ in two divided doses for six months to 18 months but more recently it is being used as $2-2.5 \mathrm{mg} / \mathrm{kg}$ as singe alternate day or as daily dose for more than two years. ${ }^{6,15-17,19}$

Ekambram $S$ et al. used leva as daily single dose (2 mg/kg/day) in all children, Fu et al. and Samuel et al. used daily dose leva in children who were non-responders to alternate day dose. ${ }^{17,20}$ On the other hand, Abeyagunawardena AS et al. used daily high dose $(2.5 \mathrm{mg} / \mathrm{kg} /$ day $)$ in those children who failed to alternate $(2.5 \mathrm{mg} / \mathrm{kg} /$ day $)$ day leva and found better outcome. ${ }^{15}$ Ekambram et al. in a study from our neighboring country (Table-IV) used single daily dose in same age group (Indian vs ours $2.8 \pm 1.45$ vs ours $3.72 \pm 2.33$ years) for same duration $(18.7 \pm 6.4$ vs $15.68 \pm 9.39)$ in children with FR and SDNS as we have used in the current study ; and showed that leva was effective in $77.3 \%$ of patients which is almost similar to our study $(80.7 \%)$.Post -leva relapses were higher in our study $(1.06 \pm 0.99)$ than in an Indian study $(0.48 \pm 0.8) .{ }^{17}$ There was reduction in cumulative dose of steroid in children treated with leva (Table-I) which is similar to other studies. ${ }^{19,21,22}$ 
Levamisole has been compared recently in RCT with MMF by Sinha A et al. and found that leva and MMF are equally effective ( $40.8 \%$ vs. $34.2 \%)$ in maintaining remission and in preventing relapses $(14.5 \%$ vs. $16.4 \%)$ without significant toxicity in children with FR and SDNS. ${ }^{23}$ We also did not find significant adverse effects suggesting safety of drug as observed by others..$^{20-24}$ Considering the results of Sinha A et al. in above RCT, Vivarelli $\mathrm{M}$ et al. also suggested use levamisole in FR/ SD. ${ }^{25}$ Levamisole is also under investigation as adjuvant agent after induction of remission with daily dose in children during first episode of nephrotic syndrome to prevent future relapses and morbidity associated with long term steroid therapy. ${ }^{14}$

Strength and limitations of this study: It is a retrospective data, lack of equal number of FR and SD, use of different dosage schedule (daily in 33 and alternate day in 48 cases), lack of strict definition of effectiveness which may have led to exclusion of SD cases who were switched to cyclophosphamide/CNI before completion of 6 months of minimum duration, lack of strict monitoring for side effects like anti-nuclear cytoplasmic antibodies (ANCA) and variation of steroid dosage for treatment of relapse which was high during initial years and lower in the later years of practice as reported previously. ${ }^{12}$

The strength of this study is sufficient number of cases, for long duration of follow up by experienced pediatric nephrologist in a tertiary care center, reflecting the variations in personal practice depending upon the available evidence over a period of more than decade from developing country.

\section{CONCLUSION}

We found that levamisole was effective in maintaining remission in $90 \%$ while on treatment, whereas remission was maintained after discontinuation in $76.4 \%$ cases. We recommend that levamisole may be tried as first line steroid sparing agent before embarking on other immunosuppressive therapies in children with FR/SDNS. However, more studies are needed to provide evidence of the optimal duration, efficacy and optimal dose and its dosage schedule in these children.

Financial Disclosures: No grant received for this study.
Conflict of Interest: Authors declared competing interest none.

\section{REFERENCES}

1. Noone DG, lijima K, Parekh R. Idiopathic nephrotic syndrome in children. Lancet. 2018;392(10141):P61-P74. doi: 10.1016/S0140-6736(18)30536-1

2. Lane JC. Pediatric Nephrotic Syndrome Treatment and Management; adverse effects of drugs. Medscape Updated: Oct 24, 2018, accessed 19 $9^{\text {th }}$ Jan 2020

3. Chis Kemper MJ, Valentin L, Husen M. Difficult-to-treat idiopathic nephrotic syndrome: established drugs, open questions and future options. Pediatr Nephrol. 2018;33:16411649. doi: 10.1007/s00467-017-3780-7

4. Cattran DC, Feehally J, Cook HT, Fervenza FC, Floege J, Gipson DS, et al. KDIGO Clinical Practice Guideline for Glomerulonephritis. Kidney Disease: Improving Global Outcomes (KDIGO) Glomerulonephritis Work Group. Kidney Int Suppl. 2012;(2):139-274.

5. Raja K, Parikh A, Webb H, Hothi D. Use of a low-dose prednisolone regimen to treat a relapse of steroidsensitive nephrotic syndrome in children. Pediatr Nephrol. 2017;32:99-105. doi: 10.1007/s00467-016-3458-6

6. Gruppen MP, Bouts AH, Jansen-van der Weide MC, Markus MP, Zurowska A, Maternik M, et al. A randomized clinical trial indicates that levamisole increases the time to relapse in children with steroid-sensitive idiopathic nephrotic syndrome. Kidney Int. 2018;93:510-518. doi: 10.1016/j. kint.2017.08.011

7. Iijima K, Sako M, Kamei K, Nozul K. Rituximab in steroidsensitive nephrotic syndrome: lessons from clinical trials. Pediatr Nephrol. 2018;33:1449-1455. doi: 10.1007/s00467017-3746-9

8. Szeto C, Gillespie KM, Mathieson PW. Levamisole induces interleukin-18 and shifts type 1 /type 2 cytokine balance. Immunology. 2000;100:217-224.

9. Bajeer IA, Sabeeta K, Tresa V, Hashmi S, Mubarak M, Lanewala AA. Histopathological Spectrum and ShortTerm Outcome of Treatment with Cyclophosphamide in Relapsing Steroid-Sensitive Nephrotic Syndrome. J Coll Physician Surg Pak. 2018;28(6):436-439. doi: 10.29271/ jcpsp.2018.06.436

10. Hafeez F, Ahmed TM, Samina U. Levamisole in Steroid dependent and frequent relapsing nephrotic syndrome. J Coll Physician Surg Pak. 2006;16(1)35-37.

11. Sherali AR, Moorani KN, Chishty SH. Response to Cyclosporin A in Pakistani Children with Steroid Resistant Focal Segmental Glomerulosclerosis. Pak Pediatr J. 2010;34(1):3-7.

12. Moorani KN, Hotchandani HM, Zubair AM, Lohana NC, Veerwani NR. Immunosuppressive therapy in children with primary nephrotic syndrome: single center experience, Karachi, Pakistan. BMC Nephrol. 2019;20:239-247. doi: 10.1186/s12882-019-1347

13. Muhlig AK, Lee JY, Kemper MJ, Kronbichler A, Yang JW, Lee JM, et al. Levamisole in Children with Idiopathic Nephrotic Syndrome: Clinical Efficacy and Pathophysiological Aspects. J Clin Med. 2019;8(6):860-876 doi: 10.3390/jcm8060860

14. Veltkamp F, Khan DH, Reefman C, Veissi S, Van Oers HA, Levtchenko E, et al. Prevention of relapses with levamisole as adjuvant therapy in children with a first episode of idiopathic nephrotic syndrome: study protocol for a double blind, randomised placebo-controlled trial (the LEARNS study). BMJ Open. 2019;9:e027011. doi: 10.1136/ bmjopen-2018-027011 
15. Abeyagunawardena AS, Karunadasa U, Jayaweera $\mathrm{H}$, Tennakoon S, Abeyagunawardena S. Efficacy of higher-dose levamisole in maintaining remission in steroid-dependent nephrotic syndrome. Pediatr Nephrol. 2017;32(8):1363-1367. doi: 10.1007/s00467017-3616-5.

16. Elmas AT, Tabel Y, Elmas ON. Long- and short-term efficacy of levamisole in children with steroid-sensitive nephrotic syndrome. Int Urol Nephrol. 2013;45:1047-1055. doi: 10.1007/s11255-012-0241-x

17. Ekambaram S, Mahalingam V, Nageswaran P, Udani A, Geminiganesan S, Priyadarshini S. Efficacy of Levamisole in Children with Frequently Relapsing and Steroid-dependent Nephrotic Syndrome. Indian Pediatr. 2014;51:371-373, doi: 10.1007/s1331

18. Madani A, Isfahani ST, Rahimzadeh N, Fereshtehnejad SM, Hoseini R, Moghtaderi M, et al. Effect of Levamisole in Steroid-Dependent Nephrotic Syndrome. Iran J Kidney Dis. 2010;4(4):292-296.

19. Pravitsitthikul N, Willis NS, Hodson EM, Craig JC. Non-corticosteroid immunosuppressive medications for steroid-sensitive nephrotic syndrome in children. Cochrane Database Syst Rev. 2013;10:CD002290

20. Fu LS, Shien CY, Chi CS. Levamisole in steroid-sensitive nephrotic syndrome children with frequent relapses and steroid dependency: Comparison of daily and every-other day usage. Nephron Clin Pract. 2004;97:137-141

21. Alsaran K, Mirza K, Al-Talhi A, Al-Kanani E. Experience with second line drugs in frequently relapsing and steroid dependent childhood nephrotic syndrome in a large Saudi center. Inter J Pediatr Adolesc Med 2017. doi: 10.1016/ j. ijpam.2017.03.002
22. Samuel EMK, Krishnamurthy S, Bhanudeep S, Muske S. Levamisole in frequently -relapsing and steroid -dependent nephrotic syndrome. Indian Pediatr. 2017;54:831-834

23. Sinha A, Puraswani M, Kalaivani M, Goyal P, Hari P, Bagga A. Efficacy and safety of mycophenolate mofetil versus levamisole in frequently relapsing nephrotic syndrome: an open-label randomized controlled trial. Kidney Int. 2018. doi: 10.1016/ j.kint.2018.08.039

24. Mroczkowska EK, Skrzyypczyk P, Tomaszewska MP. Levamisole therapy in children with frequently relapsing and steroid-dependent nephrotic syndrome: A single -center experience. Cent Eur J Immunol. 2016;41(3):243-247.

25. Vivarelli M, Emma F. Levamisole for children with nephrotic syndrome: new evidence for the use of an "old" drug. Kidney Int. 2019; 95:25-28. doi: 10.1016/j.kint.2018.10.008

\section{Authors' Contributions:}

KNMhasmajorcontributionfromconceptualization, manuscript writing and preparation, final editing and is responsible for integrity of research.

HMH: Literature search and referencing, data collection and write up.

AMZ: Literature search, data computation and write up.

NRV: Data collection and write up.

All authors have read and approved the final manuscript.
Authors:

1. Khemchand N Moorani, FCPS, MCPS, MBBS. Professor of Pediatric Nephrology,

2. Aasia Mohammad Zubair, FCPS, MBBS. Medical Officer,

3. Nanga Ram Veerwani, FCPS, MBBS. Medical Officer,

4. Harnam Jaichand Hotchandani, MBBS. Senior Medical Officer,

1-4: Department of Pediatric Nephrology, The Kidney Center Postgraduate Training Institute, Karachi Sindh, Pakistan.

1,2: Department of Pediatric Nephrology, National Institute of Child Health, JSMU, Karachi, Pakistan. 